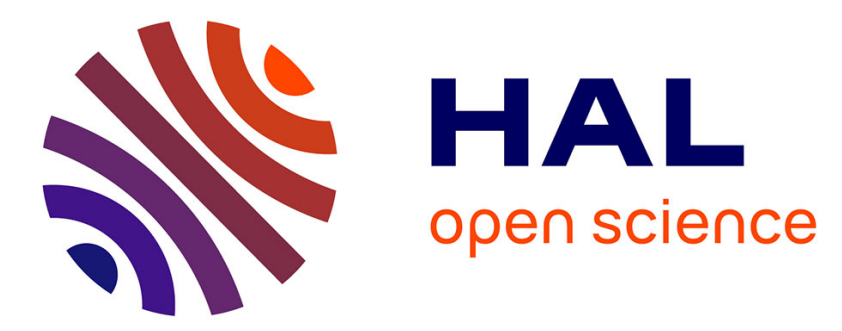

\title{
Synthesis of a [20]phenacene dodeca-ester by controlled condensation of seven naphthalene-based building blocks
}

Guillaume Naulet, Stéphanie Huet-Exiga, Harald Bock, Fabien Durola

\section{To cite this version:}

Guillaume Naulet, Stéphanie Huet-Exiga, Harald Bock, Fabien Durola. Synthesis of a [20]phenacene dodeca-ester by controlled condensation of seven naphthalene-based building blocks. Organic Chemistry Frontiers, 2019, 6 (7), pp.994-997. 10.1039/c9qo00125e . hal-02124316

\section{HAL Id: hal-02124316 https://hal.science/hal-02124316}

Submitted on 14 May 2019

HAL is a multi-disciplinary open access archive for the deposit and dissemination of scientific research documents, whether they are published or not. The documents may come from teaching and research institutions in France or abroad, or from public or private research centers.
L'archive ouverte pluridisciplinaire HAL, est destinée au dépôt et à la diffusion de documents scientifiques de niveau recherche, publiés ou non, émanant des établissements d'enseignement et de recherche français ou étrangers, des laboratoires publics ou privés. 


\title{
Synthesis of a [20]phenacene dodeca-ester by controlled condensation of seven naphthalene-based building blocks
}

\author{
Guillaume Naulet, ${ }^{\text {a }}$ Stéphanie Huet-Exiga, ${ }^{a}$ Harald Bock ${ }^{a}$ and Fabien Durola*a
}

Complementary protecting techniques for the Perkin reaction between arylacetic acids and arylglyoxylic acids efficiently allowed the multistep condensation of seven naphthalene fragments, linked by maleate bridges. Photocyclisation of this heptameric flexible precursor has led to a [20]phenacene dodeca-ester, the longest known phenacene to date.

From a conceptual point of view the thinnest graphene nanoribbons are ladder-type polycyclic aromatic compounds ${ }^{1}$ composed of only one row of fused benzene rings, allowing two different very regular structures: polyacenes and polyphenacenes. Long acenes, made of linearly fused benzene rings, are very sensitive to oxidation due to minimal sextet stabilization, and are thus too unstable to be isolated if not functionalized by very specific substituents. ${ }^{2}$ On the contrary, phenacenes are fully Fries-stabilized since their benzene rings are fused in a zig-zag way that allows the representation of a Kekulé formula where all hexagons are made of three double and three single bonds. $^{3}$ Short [3]-, [4]-, [5]- and [6]phenacenes are respectively known as phenanthrene, chrysene, picene and fulminene, and can be extracted from coal $\operatorname{tar}^{4}{ }^{4}$ whereas their longer homologs have to be synthesized from smaller fragments. Mallory and coworkers have shown that photochemical $6 \pi$-electrocyclisation ${ }^{5}$ (or "photocyclisation" for simplicity) of stilbenoïd flexible precursors is an efficient approach for such syntheses, and applied it first to the formation of an alkyl-substituted [7]phenacene, by light-induced creation of a carbon-carbon bond between two condensed monofunctional phenanthrenes. ${ }^{6}$ They subsequently adapted this strategy to the formation of the [11]phenacene 1 by double photocyclisation of a flexible precursor (Figure 1), obtained by condensation of one bifunctional and two monofunctional alkyl-substituted phenanthrene-based building blocks. ${ }^{7}$ In these two cases, flexible aliphatic substituents are necessary to improve the solubility of the precursors and of the final polycyclic aromatic compounds.

For the last 5 years, our research group has focused on the development and the application of the glyoxylic Perkin reaction to the formation of large polycyclic aromatic compounds with a wide diversity of structures: Linear or macrocyclic, planar or twisted. ${ }^{8}$ This Perkin condensation of arylglyoxylic acids with arylacetic acids, followed by same-pot esterification, leads to the formation of long flexible conjugated compounds composed of several aryl fragments linked by dialkyl maleate bridges. Therefore, besides its high efficiency, this method has the advantage of using only one active function, i.e. acetic or glyoxylic acid, for both the condensation reaction and the creation of a solubilizing flexible substituent, which significantly simplifies the synthesis of the building blocks. Contrary to alkyl substituents, these adjacent ester functions can later be transformed into other diesters or even into cyclic maleimides in order to modulate the solubility or the electronic properties of the final compounds. $^{9}$

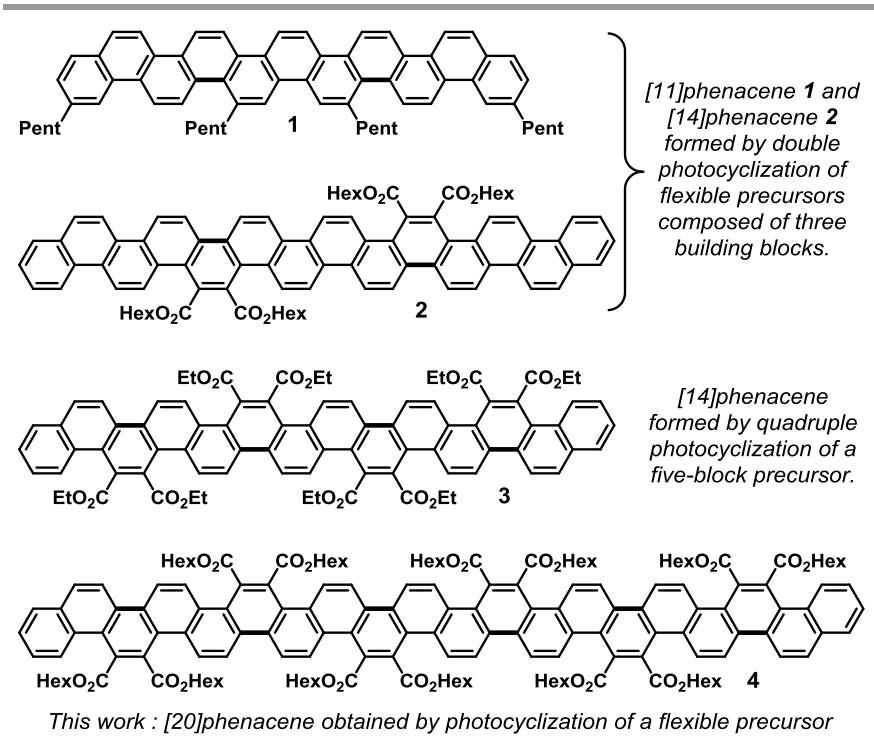

This work: [20]phenacene obtained by photocyclization of a flexible precursor
composed of seven naphthalene-based units linked by maleate bridges.

Figure 1: Substituted long phenacenes obtained by multiple photocyclisations.

Following this strategy and inspired by Mallory's approach, we have recently reported the syntheses of tetracarboxysubstituted [8]-, [10]-, [12]- and [14]phenacenes ${ }^{10}$ by double photocyclisation of flexible precursors obtained by double Perkin condensation of three naphthalene- and/or chrysenebased building blocks. The low solubility of the [14]phenacene 2 (Figure 1), obtained from three chrysene units, indicated the limits of this three-component approach concerning the size of the starting compounds. Using longer building blocks would increase the size of the final molecule, but it would also further decrease the density of solubilizing functions at its periphery and thus further decrease its solubility.

A first solution to this problem has been found by developing a protecting technique of the acetic acid function for the Perkin reaction. ${ }^{11}$ By mono-saponification of arylacetic diesters, mono-protected bifunctional diacetic building blocks have been synthesized first, and their use in a multi-step condensation of five naphthalene-based building blocks has finally led to the formation of another [14]phenacene $\mathbf{3}$ (Figure 1 ) whose periphery is substituted by eight ester functions, and which was therefore found to be much more soluble than the previous tetra-ester [14]phenacene 2 .

In this article, we present the completion of this synthetic strategy for the formation of long but still soluble phenacenes. 
The development of complementary protecting techniques of glyoxylic acid functions for the Perkin reaction would allow the controlled condensation of more than five building blocks and could thus lead to longer soluble phenacenes, such as the [20]phenacene 4 (Figure 1) which is the result of the condensation of seven naphthalene units.

First attempts of protection of the reactive keto group of the glyoxylic acid function, by usual formation of cyclic ketals and thioketals, were unsuccessful. Ketals appeared to be too unstable in the Perkin reaction conditions, whereas thioketals were not reactive enough to efficiently undergo deprotection once the condensation reaction was made.

A counter-intuitive protecting method has been serendipitously found when performing, by mistake, a Perkin reaction with a glyoxylic ester instead of a glyoxlic acid, and then observing that the ester function remained quantitatively unreacted under these conditions. Although we cannot fully explain this mechanism, this discovery was particularly convenient due to the high similarity with the previously reported protection technique of arylacetic acids by formation of esters. ${ }^{11}$ In full analogy with these previous results, we thereupon have developed the mono-protection of bifunctional aryldiglyoxylic acid compounds by formation of mono-acid mono-ester moieties, by saponification of a diester with only one equivalent of base, following an already welloptimized procedure.

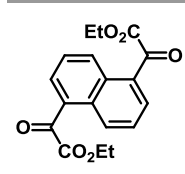

5

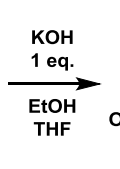

$\mathbf{5}(28 \%)$

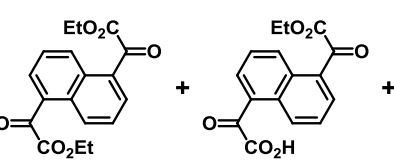

$6(49 \%)$

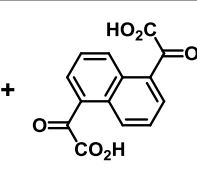

7 (impure)
Scheme 1: Synthesis of the asymmetric mono-acid mono-ester 6 by monosaponification of the diester $\mathbf{5}$.

Naphthylene-1,5-diglyoxylic diethyl ester $\mathbf{5}$ was treated in homogeneous conditions with one equivalent of potassium hydroxide in a mixture of ethanol and THF. After evaporation of the solvents and before neutralization, the solid crude mixture composed of the diacid 7 , the desired mono-acid mono-ester $\mathbf{6}$ - both as potassium salts - and the remaining diester $\mathbf{5}$ was triturated in dichloromethane (DCM). The solid mixture of acids $\mathbf{7}$ and $\mathbf{6}$ was filtered off and evaporation of the filtrate allowed recovering $28 \%$ of pure diester $\mathbf{5}$. The solid mixture containing the potassium salts of $\mathbf{6}$ and $\mathbf{7}$ was then acidified by trituration in aqueous $\mathrm{HCl}(2 \mathrm{M})$. DCM was added and a mixture containing mainly the diacid $\mathbf{7}$ and a small amount of $\mathbf{6}$ was filtered off. The organic phase of the filtrate was finally separated, dried and evaporated to afford $49 \%$ of pure mono-acid mono-ester 6 (Scheme 1). Very satisfyingly, the statistical character of this synthesis of an asymmetric mono-acid mono-ester $\mathbf{6}$ is largely compensated by a very easy and efficient separation, relying on solubility differences, of the three components of the obtained mixture.

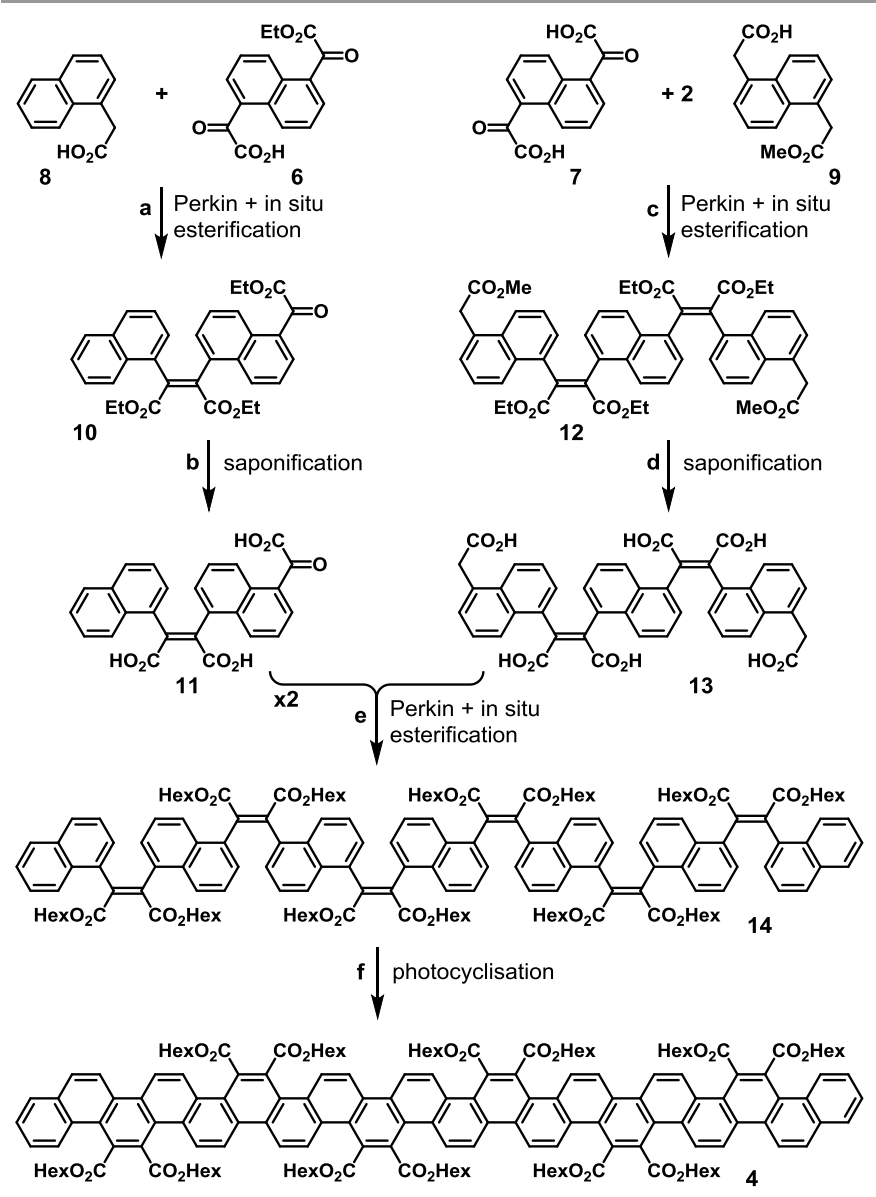

Scheme 2: Synthesis of the [14]phenacene dodeca-ester 4 via a heptameric flexible precursor 14, by Perkin condensations and final photocyclisation.

a: $\mathrm{Ac}_{2} \mathrm{O}, \mathrm{NEt}_{3}, \mathrm{THF}$, reflux, $16 \mathrm{~h}$, then $\mathrm{EtBr}, \mathrm{EtOH}, \mathrm{DBU}$, reflux, $24 \mathrm{~h}, 61 \%$; $\mathrm{b}$ : $\mathrm{NaHCO}_{3}, \mathrm{EtOH}, \mathrm{H}_{2} \mathrm{O}$, reflux, $36 \mathrm{~h}$, quantitative; c: $\mathrm{Ac}_{2} \mathrm{O}, \mathrm{NEt}_{3}, \mathrm{THF}$, reflux, $16 \mathrm{~h}$, then $\mathrm{EtBr}$, EtOH, DBU, reflux, $24 \mathrm{~h}, 96 \%$; d: $\mathrm{NaOH}$, EtOH, $\mathrm{H}_{2} \mathrm{O}$, reflux, $36 \mathrm{~h}, 86 \%$; e: $\mathrm{Ac}_{2} \mathrm{O}, \mathrm{NEt}_{3}, \mathrm{THF}$, reflux, $16 \mathrm{~h}$, then $\mathrm{HexBr}, \mathrm{HexOH}, \mathrm{DBU}$, reflux, $24 \mathrm{~h}, 53 \%$; $\mathrm{f}: \mathrm{I}_{2}$, EtOAc, UV light, rt, $10 \mathrm{~d}, 13 \%$.

The [20]phenacene dodeca-ester 4 has thereupon been synthesized following a six-step convergent synthetic strategy from four different naphthalene-based building blocks (Scheme 2): monofunctional naphthyl-1-acetic acid 8, monoprotected bifunctional naphthylene-1,5-diacetic acid 9, bifunctional naphthylene-1,5-diglyoxylic acid 7 and its monoprotected homologue 6 . Naphthyl-1-acetic acid 8 was first coupled with one equivalent of the mono-protected diglyoxylic compound 6, followed by in situ esterification of the central carboxylic functions. The resulting protected monofunctional dimer $\mathbf{1 0}$ was obtained with a yield of $61 \%$ and was then fully hydrolysed in basic conditions to afford the triacid $\mathbf{1 1}$ quantitatively. In parallel, naphthylene-1,5-diglyoxylic acid 7 was coupled with two equivalents of the mono-protected diacetic compound $\mathbf{9}$ and esterified in situ, with an excellent yield of $96 \%$. Complete saponification of this doubly protected bifunctional trimer afforded the hexa-acid $\mathbf{1 3}$ with a yield of $86 \%$. This bifunctional diacetic trimer 13 was finally coupled twice with the monofunctional glyoxylic dimer $\mathbf{1 1}$ by Perkin reaction, followed by in situ esterification of the twelve resulting carboxylic functions, yielding (53\%) the linear heptameric flexible precursor $\mathbf{1 4}$ which is composed of seven 
naphthalene fragments linked by six dihexylmaleate bridges. Long hexyl ester chains have been chosen to optimize the solubility of the dodeca-ester compounds. Finally, a sixfold photocyclisation triggered by UV light allowed the transformation of the flexible heptamer 14 into the targeted [20]phenacene dodeca-ester 4, with an isolated yield of $13 \%$ after ten days of reaction. This modest yield is partly due to the difficult separation of the fully condensed compound 4 from the mixture of incompletely cyclised intermediates.

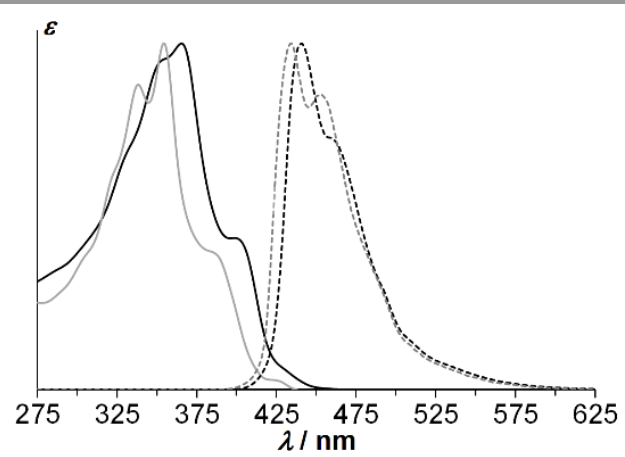

Figure 2: Normalised absorption (solid lines) and fluorescence (dotted lines) spectra of [14]phenacene 3 (grey) and [20]phenacene 4 (black) (4 $\mu \mathrm{M}$ in chloroform). Fluorescence spectra are recorded upon excitation at $350 \mathrm{~nm}$.

The optical absorption spectra of dilute chloroform solutions (Figure 2) show that the structurally regular [20]phenacene dodeca-ester 4 has an absorption maximum at $366 \mathrm{~nm}$ with close near-equal-intensity shoulder at $352 \mathrm{~nm}$ and a characteristic long-wavelength shoulder of about half-ofmaximum intensity at $399 \mathrm{~nm}$, similar to the previously reported phenacene tetra- and octa-esters. ${ }^{10,11}$ The fluorescence spectrum, with maximum at $441 \mathrm{~nm}$ and a shoulder $462 \mathrm{~nm}$, mirrors the shouldered main absorption peak. In comparison, the previously reported [14]phenacene octa-ester 3 shows two close main absorption peaks at 354 and $338 \mathrm{~nm}$ and a long-wavelength shoulder at $387 \mathrm{~nm}$, and two close fluorescence peaks at 434 and $453 \mathrm{~nm}$. Thus the absorption spectrum of $\mathbf{4}$, whilst very similar in shape, redshifts by about $12 \mathrm{~nm}$ with respect to $\mathbf{3}$, whilst the fluorescence red-shifts by about $8 \mathrm{~nm}$. This slightly smaller Stokes shift in $\mathbf{4}$ compared to $\mathbf{3}$ points to a greater rigidity in $\mathbf{4}$ that restricts structural adjustments in the excited state.

\section{Conclusions}

In summary, ester functions have been serendipitously found to be convenient protecting groups of glyoxylic acid functions during Perkin condensations, and an efficient elaboration of appropriate naphthylene-1,5-diglyoxylic mono-acid monoesters 6 as mono-protected bifunctional building blocks has been developed. A resulting sequence of several Perkin condensations and deprotecting saponifications, in conjunction with complementary mono-protected diacetic building blocks, provided a simple and systematic access to a twelve-fold carboxy-substituted heptameric oligomer 14. This has subsequently been submitted to photochemical intramolecular cyclisations to form the fully condensed and well soluble [20]phenacene dodeca-ester 4, which is the longest phenacene so far reported. Although in this specific case the final photocyclisation step presented a modest yield, the two complementary protecting techniques developed for the Perkin strategy are both very efficient and widen the limits of this synthetic approach. Thus oligo-arylenemaleates of any size, and their corresponding nanoribbon-style cyclisation products, are now straightforwardly targetable, including macrocyclic species. ${ }^{12}$

\section{Notes and references}

1 a) K. Chmil and U. Scherf, Makromol. Chem., Rapid Commun., 1993, 14, 217; b) J. Lee, H. Li, A. J. Kalin, T. Yuan, C. Wang, T. Olson, H. Li and L. Fang, Angew. Chem. Int. Ed., 2017, 56, 13727 ; c) C. Li, C. Liu, Y. Li, X. Zhua and Z. Wang, Chem. Commun., 2015, 51, 693.

2 W. Fudickar and T. Linker, J. Am. Chem. Soc., 2012, 134, 15071.

3 a) A. Ciesielski, T. M. Krygowski and M. K. Cyrański, Symmetry, 2010, 2, 1390; b) A. Graovac, I. Gutman, M. Randić and N. Trinajstić, J. Am. Chem. Soc., 1973, 95, 6267; c) K. Fries, Liebigs Ann. Chem., 1927, 454, 121.

4 K. F. Lang, Buffleb and J. Kalowy, Chem. Ber., 1964, 97, 494.

5 Reviews about light-induced $6 \pi$-electrocyclisations: a) K. B. Jørgensen, Molecules, 2010, 15, 4334; b) F. B. Mallory, C. W. Mallory, Org. React., 1984, 30, 1; Recent examples: c) F. B. Mallory, C. K. Regan, J. M. Bohen, C. W. Mallory, A. A. Bohen and P. J. Carroll, J. Org. Chem., 2015, 80 , 8; d) M. K. Węcławski, M. Tasior, T. Hammann, P. J. Cywiński and D. T. Gryko, Chem. Comm., 2014, 50, 9105; e) A. D. D. Wonanke, J. L. Ferguson, C. M. Fitchett and D. L. Crittenden, Chem. Asian J., 10.1002/asia.201801761.

6 F. B. Mallory, K. E. Butler, A. C. Evans and C. W. Mallory, Tetrahedron Lett., 1996, 37, 7173.

7 F. B. Mallory K. E. Butler, A. C. Evans, E. J. Brondyke, C. W. Mallory, C. Yang and A. Ellenstein, J. Am. Chem. Soc., 1997, 119, 2119.

8 a) P. Sarkar, F. Durola and H. Bock, Chem. Commun., 2013, 49, 7552; b) H. Bock, P. Carré, E. A. Hillard and F Durola, Eur. J. Org. Chem., 2015, 1028; c) H. Bock, S. Huet, P. Dechambenoit, E. A. Hillard and F. Durola, Eur. J. Org. Chem., 2015, 1033; d) A. Robert, P. Dechambenoit, H. Bock and F. Durola, Can. J. Chem.; 2017, 95, 450; e) M. Ferreira, G. Naulet, H. Gallardo, P. Dechambenoit, H. Bock and F. Durola, Angew. Chem. Int. Ed., 2017, 56, 3379; f) A. Robert, P. Dechambenoit, E. A. Hillard, H. Bock and F. Durola, Chem. Commun., 2017, 53, 11540.

9 a) M. Ferreira, E. Girotto, A. Bentaleb, E. A. Hillard, H. Gallardo, F. Durola and H. Bock, Chem. Eur. J., 2015, 21, 4391; b) E. Girotto, M. Ferreira, P. Sarkar, A. Bentaleb, E. A. Hillard, H. Gallardo, F. Durola and H. Bock, Chem. Eur. J., 2015, 21, 7603.

10 T. S. Moreira, M. Ferreira, A. Dall'armellina, R. Cristiano, H. Gallardo, E. A. Hillard, H. Bock and F. Durola, Eur. J. Org. Chem., 2017, 4548.

11 G. Naulet, A. Robert, P. Dechambenoit, H. Bock and F. Durola, Eur. J. Org. Chem., 2018, 619.

12 G. Naulet, L. Sturm, A. Robert, P. Dechambenoit, F. Röhricht, R. Herges, H. Bock and F. Durola, Chem. Sci., 2018, 9, 8930. 